\title{
Dança como conteúdo da educação física escolar
}

\author{
Dance as content of school physical education
}

Danza como contenido de la educación física escolar

\author{
iD Carla Elisa Santana Soares \\ Universidade Estadual de Feira de Santana, Feira de Santana, Bahia, Brasil \\ carlaelisasoares@hotmail.com \\ (iD) Jaqueline Rodrigues da Silva \\ Secretaria de Educação do Estado da Bahia, Feira de Santana, Bahia, Brasil \\ jaquejrs@yahoo.com.br
}

\begin{abstract}
Resumo: O objetivo desta pesquisa foi analisar a concepção da dança como conteúdo da educação física escolar, expressa nos artigos publicados na Revista Brasileira de Ciências do Esporte (RBCE). Trata-se de pesquisa bibliográfica em que foram analisados 10 artigos. Encontramos em maior abundância as concepções da dança como linguagem, linguagem simbólica ou forma de comunicação e maior incidência do referencial fenomenológico. Apontamos a necessidade de aprofundamentos sobre o tipo de sujeito que se quer formar a partir das concepções citadas. Por fim, fazemos a defesa do ensino da dança na escola a partir da concepção de formação omnilateral.
\end{abstract}

Palavras-chave: Educação Física. Dança. Cultura Corporal.

Abstract: The objective of this research was to analyze the conception of dance as content of school physical education, expressed in the articles published in the Brazilian Journal of Sports Sciences (RBCE). It is a bibliographical research in which 10 articles were analyzed. We show in greater abundance the conceptions of dance as language, symbolic language or form of communication, and higher incidence of 
the phenomenological referential. We point out the need for deepening on the type of subject that one wants to form from the conceptions mentioned. Finally, we make the defense of the teaching of dance in the school from the conception of omnilateral formation.

Keywords: Education Physical. Dance. Body Culture.

Resumen: El objetivo de esta investigación fue analizar la concepción de danza como contenido de la educación física escolar, expresa en los artículos publicados en la Revista Brasileña de Ciencias del Deporte (RBCE). Es una investigación bibliográfica en la cual fueron analizados 10 artículos. Evidenciamos en mayor abundancia las concepciones de danza como lenguaje, lenguaje simbólico o manera de comunicación y mayor incidencia del referencial fenomenológico. Aponemos la necesidad de profundizaciones sobre el tipo de sujeto que se quiere formar a partir de las concepciones citadas. Por último, hacemos la defensa de la enseñanza de la danza en la escuela a partir de la concepción de la formación omnilateral.

Palabras-clave: Educación Física. Danza. Cultura Corporal.

Submetido em: 05-11-2018

Aceito em: 28-07-2020 


\section{Introdução}

Partimos do pressuposto de que a dança deve ser ensinada na escola como um conteúdo da disciplina Educação Física, que deve ser tratado metodologicamente para garantir o processo de transmissão dos conhecimentos. Entretanto, vivemos em tempos de negação do conhecimento, redução da relevância social dos professores e da escola, do esvaziamento do conhecimento científico nos currículos de educação básica e profissional, além dos retrocessos causados pela fragmentação da formação (DUARTE, 2003).

Concepções pedagógicas, metodológicas, teorias do conhecimento, proposições de ensino, teorias educacionais, concepções de formação humana e projetos de sociedade estão presentes nas aulas, livros didáticos, documentos educacionais e, portanto, também perpassam pelas publicações que compõem o processo de formação de professores. Mesmo que não apresentados com ênfase em projetos político-pedagógicos e planos de ensino, são alicerce do trato com o conhecimento (FREITAS, 1995).

A partir desses elementos emergiu a pergunta norteadora de nossas reflexões: no campo da educação física o que tem se constituído enquanto concepção de dança? Para alcançarmos a resposta para essa questão, elegemos como campo de análise a Revista Brasileira de Ciências do Esporte (RBCE), pois, dentre os órgãos científicos atrelados à educação física, o Colégio Brasileiro de Ciências do Esporte (CBCE) se consolidou como uma respeitável instituição e de relevante alcance bibliográfico nos cursos de formação, pois se propõe a fomentar discussões relevantes da área em diferentes vertentes, como a biomecânica, fisiologia, educação e psicologia, para além do que o nome da instituição propõe: "ciências do esporte" (MALINA, AZEVEDO e OLIVEIRA, 2007; RBCE, 2016.).

Em 1979, o CBCE iniciou as edições da Revista Brasileira de Ciências do Esporte (RBCE) com a tarefa de possibilitar a circulação da produção do conhecimento e problemáticas da educação 
física entre os profissionais e estudantes da área. Nesse percurso "a RBCE vem registrando a história da Educação Física brasileira a partir de diferentes olhares e concepções, de distintas abordagens, temas, objetos e problematizações" (RBCE, 2016).

Assim, definimos como objetivo geral: analisar a concepção de dança, como conteúdo da educação física escolar, expressa nos artigos publicados na RBCE. Como objetivos específicos elencamos: a) identificar os artigos originais que versam sobre a dança; b) averiguar a concepção de ensino/educação expressa nos documentos; c) apontar as implicações pedagógicas.

Nossa reflexão se desenvolverá na seguinte estrutura: 1 - descrição da metodologia utilizada; 2 - exposição analítica, subdividida em: a) revisão da literatura, com diálogos sobre concepções de dança e a dança como conteúdo da educação física escolar, b) exposição dos dados explorados e interação referencial; 3) considerações finais.

\section{Metodologia}

Trata-se de uma pesquisa bibliográfica que, de acordo com Lakatos (2003), utiliza a bibliografia pública. Definimos como técnica de pesquisa a análise de conteúdo por ter como objetivo "a manipulação de mensagens (conteúdo e expressão desse conteúdo), para evidenciar os indicadores que permitam inferir sobre uma outra realidade que não a da mensagem" (BARDIN, 2009, p. 46). A fonte de pesquisa foram artigos completos publicados na RBCE, que de forma direta ou indireta tratam sobre a dança na escola.

Na pré-análise, houve o levantamento do material publicado desde a primeira edição até segunda de 2016. Na primeira seletiva, utilizamos como critério de inclusão: 1 - títulos com a palavra "dança"; 2 - artigos completos. Assim, descartamos resumos e obras com outras temáticas. Resultado: 17 artigos. Na exploração do material, estabelecemos como critério de exclusão: artigos 
que não tratassem da dança como conteúdo de ensino na escola. Resultado para análise final: 10 artigos (ver Tabela 1).

Para tratamento dos resultados, inferência e interpretação, foram utilizadas categorias analíticas e de conteúdo. As analíticas foram: mediação e contradição. Segundo Kuenzer (1998), a categoria mediação articula os elementos e dimensões concreta e abstrata da pesquisa; a categoria contradição trata da relação dialética da lei dos contrários, que segue em busca da compreensão dos dados da realidade, para identificar onde se incluem/excluem e onde possibilitam o desaparecimento/surgimento de outra realidade (KUENZER, 1998).

Os dados da pesquisa possibilitaram eleger como categorias de conteúdo: concepção de dança e prática pedagógica. A "concepção de dança" se expressa na forma como os autores e autoras sintetizam suas compreensões sobre aquilo que constitui a dança, enquanto a prática pedagógica é vista sob a ótica de influências que pode haver no ensino daquele conteúdo a partir de determinada concepção.

\section{A dança como atividade humana: breves considerações}

As discussões que definem a dança como campo de análise empírico são de diversas vertentes teóricas. Partimos da compreensão que a dança é uma atividade essencialmente humana, "encontram-se pessoas com movimentos semelhantes aos de um gato, doninha ou cavalo, mas nunca ninguém viu um cavalo, uma doninha ou um gato exibindo movimentos semelhantes aos humanos" (LABAN, 1978, p. 33).

A dança faz parte da cultura desde os povos primitivos. Está no conjunto de produções humanas que não modificam diretamente a natureza, mas se constrói a partir dessa interação: homem e natureza.

Soares (2014, p. 30-31) descreve a dança como 
manifestação da cultura corporal, que se caracteriza como uma atividade humana que se desenvolveu como produto do trabalho. Suas sistematizações, tendências, significações, criações e ampliações são objetivações das alterações históricas construídas no seio das relações sociais; os seus sentidos e significados - mesmo que não consciente - são expressões específicas da intencionalidade da atividade humana, sendo determinante e determinada pela forma como é produzida e reproduzida socialmente a vida - modo de produção'. Suas dimensões (rítmicas, estéticas, artísticas, educativas, filosóficas, econômicas, históricas, etc.) e fundamentos são apropriadas de diferentes formas a partir das possibilidades concretas de acesso à cultura/cultura corporal.

Por isso, apontamos que pensar o ensino de dança apartado das relações sociais é reduzir o ato de dançar a si mesmo. Não existiria dança sem relações sociais, sem produção de cultura, sem trabalho. Os alunos precisam aprender isso e não apenas os movimentos que os permitem dançar! A cultura corporal é
uma construção sócio histórica que depende do modo de vida, do modo de organizar a produção de bens materiais e imateriais e isto não pode ser visto isolado a partir de indivíduos, [...] tem que ser encarado historicamente, a partir da totalidade da espécie humana, do gênero humano, a partir da luta de classes" (TAFFAREL, 2012, p. 163).

Para Rinaldi (2011), o ensino da dança na escola deve atrelar a potencialidade da criatividade, expressão e comunicação aos conhecimentos críticos, estéticos, educativos e outros, no sentido de levar os alunos a conhecerem o que há para além e por trás do que é disseminado pela mídia. A dança é uma "[...] forma de conhecimento, de experiência estética e de expressão do ser humano,

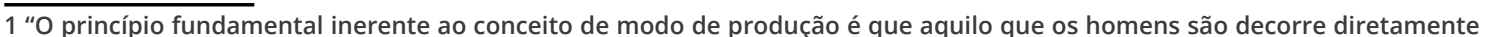
do modo como eles produzem sua existência. Em consequência, o modo de produção determina todas as manifestações da existência humana, desde as formas da produção dos bens materiais destinados ao consumo e à troca, até as formas da consciência. Portanto, a forma de manifestação da educação também irá variar de maneira correspondente à variação do conceito de modo de produção" (SAVIANI, 2009, p. 11).
} 
pode ser elemento de educação social do indivíduo" (MARQUES, 1999, p.16).

Brasileiro (2009) diz que uma visão romântica da dança pode nos levar a pontuar que "dança é tudo", por se expressar enquanto manifestação cultural de várias formas como rituais, expressão de sentimentos, por contar e recontar histórias, todavia, o que nos leva a definir o que é a dança é a função social que ela cumpre nas relações sociais.

\section{O "lugar" da dança na escola}

Os professores precisam estar "atentos ao fato de que a escola deve dialogar com a sociedade em transformação, ela é um lugar privilegiado para que o ensino de dança se processe com qualidade, compromisso e responsabilidade" (MARQUES, 2012, p. 5). Portanto, precisam dominar os conceitos, a história do conteúdo, as classificações, aspectos estruturantes, para que possam identificar o grau de desenvolvimento cognitivo dos alunos e de aproximação com o conteúdo a ser ensinado (COLETIVO DE AUTORES, 2012).

Os frutos da produção humana, incluindo o conhecimento científico, não estão disponíveis a todos os indivíduos de forma igualitária. A diferença entre os indivíduos "é o produto da desigualdade econômica, da desigualdade de classes e da diversidade consecutiva das suas relações com as aquisições que encarnam todas as aptidões e faculdades da natureza humana" (LEONTIEV, 1978, p. 268).

Segundo Saviani (2012, p. 14) "a escola diz respeito ao conhecimento elaborado e não ao conhecimento espontâneo; ao saber sistematizado e não ao saber fragmentado". Todavia, a dança que tem entrado na escola não tem ultrapassado os limites do cotidiano, ou seja, desse saber fragmentado.

Dos Santos e Chaves Figueiredo (2006) falam que, apesar de a dança contribuir para o alargamento da aprendizagem e a for- 
mação humana, sua presença na escola está desvinculada de um projeto político-pedagógico e, quando não é negada em sua totalidade, aparece em projetos extracurriculares com sentidos e significados educacionais não esclarecidos e sem objetivos definidos. Mais de uma década se passou e continuamos a dialogar sobre as mesmas questões, ou seja, elas não foram superadas.

[...] a dança também está presente, nas salas, corredores, pátios, áreas de acesso, quadras. E lá estão as possibilidades de dança que vimos na rua, na tv, no cinema, nas festas populares, e até mesmo ali, nas escolas. Mas quase nunca nas salas de aula, como conhecimento integrante da cultura escolar (BRASILEIRO, 2009, p. 8).

As aulas podem ser prisões de ideias, de padrões estéticos, prazeres, posturas, repertórios, impostos pelos padrões hegemônicos. Não se pode mais ignorar o papel social, cultural e político da cultura corporal. Apenas uma visão histórica ingênua poderia entender que a dança não passa de "uns passinhos a mais ou a menos nas vidas das pessoas" (MARQUES, 1997).

Todo conhecimento pode educar, tanto o conhecimento popular como o conhecimento científico. O que os diferenciam são os seus sentidos e significados e a forma como são estruturados. A escola deve se ocupar de uma formação crítica, direcionada a compreender as complexas relações sociais de desigualdade entre as classes, bem como as bases que influenciam a construção dos conhecimentos espontâneos e dos científicos; identificar de que forma a dança pode contribuir significativamente para a formação dos sujeitos que só terão acesso ao saber sistematizado naquele local.

\section{A “dança” na escola: análise das publicações da RBCE}

A inferência aqui realizada não tem a pretensão de se constituir como verdade absoluta e imutável, trata-se de uma análise que 
segue um padrão metodológico e um direcionamento referencial. Entendemos que as publicações são impactadas pela realidade complexa e contraditória em que estão inseridas, por influências teóricas e por fatores que circundam os processos de formação.

A primeira, é a de reafirmação da necessidade de aprofundar os estudos e proposições sobre a dança como conteúdo de educação física escolar. O último artigo completo encontrado na RBCE sobre a temática foi publicado em 2011, ou seja, o tema tem deixado de circular através desse periódico.

Notemos:

Tabela 1: artigos completos, publicados na rbce entre 1994 e 2016, que tratam da dança na escola.

\begin{tabular}{|c|c|c|c|}
\hline$N^{\circ}$ & AUTORIA & TítULo & ANO \\
\hline 01 & ANDRADE, C. F. P. et al & $\begin{array}{c}\text { Proposta dança/educação: Por que, como } \\
\text { e pra quê? }\end{array}$ & 1994 \\
\hline 02 & GEHRES, A. F. & $\begin{array}{c}\text { Avaliação em dança nas aulas de } \\
\text { Educação Física: 30 ciclo das escolas } \\
\text { básicas 2,3 do conselho de Oeiras- } \\
\text { Portugal }\end{array}$ & 1997 \\
\hline 04 & DANTAS, M. F.; SANTIN, S. & $\begin{array}{c}\text { Metodologia do ensino da dança: } \\
\text { tematizando fatos folclóricos }\end{array}$ & 1997 \\
\hline 05 & MAYER, A. M. M. & $\begin{array}{c}\text { Um "olhar" fenomenológico sobre } \\
\text { o processo criativo em composição } \\
\text { coreográfica na área de dança-educação }\end{array}$ & 1999 \\
\hline 06 & PACHECO, A. J. P. & $\begin{array}{c}\text { A dança na Educação Física: uma revisão } \\
\text { da literatura }\end{array}$ & 1999 \\
\hline 07 & LARA, M. L. et al & $\begin{array}{c}\text { As danças na mídia e as danças na escola } \\
\text { Dança e ginástica nas abordagens } \\
\text { metodológicas da Educação Física escolar }\end{array}$ & 2002 \\
\hline 08 & PORPINO, K. O; TIBÚRCIO, L. K. O. M. & $\begin{array}{c}\text { Cenas urbanas e cenas da dança: } \\
\text { compondo novos repertórios } \\
\text { pedagógicos no contexto do ensino } \\
\text { superior }\end{array}$ & 2007 \\
\hline 09 & BUOGO, E. C. B; LARA, L. M. & $\begin{array}{c}\text { Análise da dança como conteúdo } \\
\text { estruturante da Educação Física nas } \\
\text { diretrizes curriculares da educação básica } \\
\text { do Paraná }\end{array}$ & 2011 \\
\hline & SARAIVA, M. C. & $\begin{array}{c}\text { Elementos para uma concepção de dança } \\
\text { na escola: a perspectiva da educação }\end{array}$ & 2009 \\
\hline
\end{tabular}


A partir dessas leituras identificamos que quatro concepções de dança são mais expressivas (ver Tabela 2). Em algumas publicações foram identificadas mais de uma concepção.

Vejamos:

Tabela 2: Análise das concepções de dança encontradas nos artigos publicados na RBCE.

\begin{tabular}{|c|c|}
\hline CONCEPÇÃo DE DANÇA & $\begin{array}{c}\text { \% DE } \\
\text { FREQUÊNCIA }\end{array}$ \\
\hline A dança como linguagem, linguagem simbólica ou forma de comunicação & $60 \%$ \\
\hline $\begin{array}{c}\text { Manifestação cultural que possibilita a apropriação da cultura e da } \\
\text { realidade ao mesmo tempo em que forma os próprios sujeitos }\end{array}$ & $50 \%$ \\
\hline Possui fim em si mesmo/improvisação & $20 \%$ \\
\hline Constitui-se a partir de conteúdos próprios & $20 \%$ \\
\hline Elemento da cultura corporal de movimento & $10 \%$ \\
\hline Estética & $10 \%$ \\
\hline Elemento da cultura corporal & $10 \%$ \\
\hline
\end{tabular}

As publicações que expressam a concepção com $60 \%$ de ocorrência, utilizam como referencial o entendimento da dança como fenômeno. Para a escola, fazem a defesa do ensino pela dança, ou seja, a sua utilização como método de ensino.

Este é um exemplo de como essa concepção se expressa nas publicações: artigo 09 "As práticas investigadas permitiram apresentarmos uma perspectiva de ensino "abraçada" com os objetivos de uma educação de/e para gênero, nas vivências possíveis da dança e de outras atividades expressivas na escola" (SARAIVA, 2009, p. 156).

A opção pedagógica gera uma secundarização do conteúdo da dança em si. Estudos, como o de Brasileiro (2003) e Alves et al (2015), afirmam que a dança tem sido negligenciada na escola, raramente é tratada como tendo um conhecimento próprio.

Ora, o "chão" da escola, além de ser reflexo da sociedade, reflete também os impactos causados pela formação de professores. Essa foi a concepção de dança encontrada com maior expres- 
são em um dos periódicos que se propõem a circular amplamente entre "formadores de opiniões" da educação física brasileira.

Sobre a mesma concepção, destacamos: artigo 08 "A dança vem sendo entendida como uma linguagem artística e como parte da cultura de movimento produzida pelos diversos povos, configurando-se como possibilidade de expressão, comunicação e conhecimento simbólico da cultura" (PORPINO e TIBÚRCIO, 2007, p. 142 apud PORPINO e TIBÚRCIO, 2005a; 2005b); artigo 01 "manifestação cultural inerente ao homem e uma das linguagens que o indivíduo dispõe para expressar e comunicar seus sentimentos, emoções e valores, refletindo as relações sociais e culturais". (ANDRADE, 1994, p. 29).

O que queremos ressaltar ao trazer esses trechos é a sustentação fenomenológica. Para identificar o referencial é preciso reconhecer que a caracterização da dança como linguagem simbólica está baseada em um princípio da fenomenologia, que é o princípio da "consciência intuitiva", ou seja, defende que a realidade é aquilo que é captado pela consciência. Isso significa que para que uma coisa seja analisada, sujeito e objeto devem se separar, ao mesmo tempo que há a compreensão que a dança, como manifestação cultural, faz parte da essência humana. A frase "nasceu com o dom" é uma representação dessa concepção, que retira da divisão de classes a responsabilidade sobre a desigualdade do acesso aos meios de apreensão da cultura corporal.

Analisando os princípios da fenomenologia husserliana, Barbosa (2014) noticia:

O ser verdadeiro das coisas remete aos simples aparecer dos objetos na consciência enquanto existentes, ou seja, a sua existência é o que se manifesta na evidência de acordo com certas sínteses de experiências que nos dão a aparência de um ser estável e permanente. Portanto, a realidade é o que se dá na intuição, dentro de determinadas condições, como correlato da vivência intencional da consciência. 
Parece-nos que essa perspectiva não considera que a forma como os seres humanos produzem e reproduzem socialmente a vida é determinante e determinada pelas relações sociais e pela base econômica em que se sustenta a sociabilidade. Por isso, é possível dizer que a fenomenologia capta apenas uma expressão da realidade, mas não a realidade em sua totalidade. Ancoramonos em Marx (2008, p. 47) para afirmar que "na produção social da própria existência, os homens entram em relações determinadas, necessárias, independentes de sua vontade; [...] não é a consciência do homem que determina o seu ser, mas, pelo contrário, o seu ser social é que determina a sua consciência".

Marx (ibidem) incorpora na sua teoria o que Husserl chama de "consciência" - forma que os seres humanos captam a realidade e vai além do fenomenólogo (ou seja, supera por incorporação) ao dizer que a afetividade, a expressividade, a comunicação, a consciência e tudo que provém das relações sociais, complexas e contraditórias, acontecem sobre uma base material e por múltiplas determinações.

A segunda concepção expressiva, identificada em $50 \%$ das publicações, expressam o entendimento de que a apropriação cultural acontece ao mesmo tempo em que forma os próprios sujeitos. Entretanto, não podemos analisar todas da mesma forma, pois não emergem do mesmo referencial teórico, o que causou uma heterogeneidade de proposições de ensino2: 1 - concepção fenomenológica sem clara exposição de uma proposição metodológica; 2 - teoria crítico-emancipatória; 3 - teoria crítico-superadora.

Nem todos os artigos analisados que demonstram alicerce na fenomenologia desenvolvem a concepção de dança com base na proposição crítico-emancipatória, todavia, se a proposição é crítico-emancipatória, consequentemente carrega traços da fenomenologia. Não há como retirar a teoria do conhecimento de uma

\footnotetext{
2 Na década de 80 , em movimento contra-hegemônico, foram sistematizadas algumas teorias pedagógicas da Educação Física, as mesmas sistematizam proposições que norteiam o trato com o conhecimento, ou seja, o fazer pedagógico dos professores de Educação Física, na escola. A teoria crítico-emancipatória faz parte do conjunto de teorias que não sistematizam, metodologicamente, o ensino dos conteúdos na escola; a crítico-superadora compõe o bloco de teorias sistematizadas, mesmo dentro do bloco se destaca das demais por propor um ensino superador da sociedade de classes (SILVA, 2011).
} 
proposição de ensino, essa primeira, expressa uma concepção de sociedade e do tipo de sujeito que se pretende formar.

A heterogeneidade identificada na concepção 2, "dança como manifestação cultural" expressa tentativas de incorporar as críticas existentes e de superá-las. Gehres (1997), Sborquia e Gallardo (2002), Porpino e Tibúrcio (2007) são alguns dos autores que criticam a ausência da dança no currículo escolar e fazem proposições para o seu ensino.

As outras duas concepções, encontradas com $20 \%$ de incidência, apresentam contraposições entre si nas perspectivas de ensino, mas avançam ao reconhecer a dança como conteúdo de ensino.

Observemos:

Artigo 02

Por outro lado, a exploração do movimento livre, levando à construção de composições coreográficas, permite ao aluno estabelecer relações diretas com a dança em si - a coreografia, do ponto de vista não de mero repetidor, mas sim de um manipulador de gestos e movimentos, sentidos e significados (GHERES, 1997, p. 610).

\section{Artigo 08}

Sendo possuidora de um conhecimento próprio dentro do fazer pedagógico na escola, a dança não pode ser reduzida a um meio lúdico de ensinar outros conteúdos, a uma opção para dinamizar as festividades escolares, a uma forma de catarse ou relaxamento dos alunos tão assoberbados pelas tarefas escolares ou a uma mera atividade para o condicionamento físico, apesar de algumas dessas situações poderem ser pensadas como consequência do trabalho desenvolvido a partir de uma visão interdisciplinar que não menospreze, mas inclua o conhecimento específico da dança (PORPINO e TIBÚRCIO, 2007, p. 151).

A primeira concepção unilateraliza o ensino da dança, prezando pela experiência estética. A segunda, evidencia mais a defesa 
de que a dança na escola não continue a reproduzir aquilo que ela é em outros ambientes e propõe o ensino dos conhecimentos específicos desse elemento da cultura corporal.

\section{Considerações finais}

Não podemos negar que há um árduo processo de fragmentação da formação de professores que propõe uma formação unilateral que efetive a manutenção da sociedade capitalista. Na produção do conhecimento isso não é diferente, há direcionamentos teóricos, metodológicos e de concepções que carregam uma defesa de educação, de prática pedagógica e de sociedade predeterminadas, mesmo que não anunciadas (DUARTE, 2004; ALMEIDA, 2013).

O tipo de concepção pela qual um professor faz opção demonstra que tipo de sujeito ele tem a intenção de formar. A síntese a que chegamos é que há predominância da concepção de dança enquanto linguagens (social, simbólica, comunicativa etc.), e maior direcionamento da fenomenologia, ou seja, de formação unilateral.

Fazemos a defesa de uma formação não fragmentada e, ao mesmo tempo, de como pensamos o ensino da dança na escola. Não se trata apenas de ensinar seus fundamentos, história e não ensinar a estética da dança, mas também de levar os alunos a conhecerem os elementos da realidade que possibilitem fazer relações entre a estética e a história, os espetáculos e a divisão de classes, o lugar do clássico e do popular nas relações sociais. Uma prática pedagógica que direcione a compreensão dos alunos a se perceberem como sujeitos históricos, fruto de uma sociedade complexa e contraditória, que a dança não se expressa solta no mundo, ela faz parte da totalidade da cultura, das relações sociais e da divisão socioeconômica estabelecida. 


\section{Referências}

ALMEIDA, E. F. Contribuição à crítica da formação de professores de Educação Física: uma análise do currículo da UEFS e da UFBA (Monografia). Universidade Estadual de Feira de Santana, 2013.

ALVES, M. S. et al. O ensino da dança no ensino fundamental II e ensino médio da rede estadual de Recife-PE. Pensar a Prática, Goiânia, v. 18, n. 2, abr./jun. 2015.

ANDRADE, C. F. P. et al. - Proposta dança/educação: Por que, como e pra quê? - Revista Brasileira de Ciências do Esporte. Santa Maria-RS, v. 16, n. 1, Outubro, 1994.

BARSOSA, R. B. - A ideia husserliana de fenomenologia Inconfidentia: Revista Eletrônica de Filosofia Mariana-MG, v. 2, n. 2, jan./jul. 2014.

BARDIN, L. Análise de Conteúdo. Lisboa, Portugal; Edições 70, LDA, 2009.

BRASILEIRO, L. T. - O conteúdo “dança” nas aulas de Educação Física: temos o que ensinar? Pensar a Prática 6: 45-58, jul./jun. 2002-2003.

BRASILEIRO, L. T. - Dança-educação física: (in)tensas relações. Tese de doutorado - Universidade Estadual de Campinas, Faculdade de Educação, Campinas-SP, 2009.

COLETIVO DE AUTORES. Metodologia do Ensino da Educação Física. São Paulo: Cortez, 1992.

DIAS JUNIOR, E. M. Alienação e estranhamento em Marx e a cultura corporal - Dissertação de mestrado - Universidade Federal da Bahia, Faculdade de Educação, Salvador, 2013.

DUARTE, N. Formação do indivíduo, consciência e alienação: o ser humano na psicologia de A. N. Leontiev, Cad. Cedes, Campinas, vol. 24, n. 62, p. 44-63, abr. 2004. 
DUARTE, N.. Sociedade do conhecimento ou sociedade das ilusões?: quatro ensaios crítico-dialéticos em filosofia da educação, Campinas, SP: Autores Associados, 2003.

DOS SANTOS, R. C.; CHAVES FIGUEIREDO, V. M. - Dança e inclusão no contexto escolar, um diálogo possível. Pensar a Prática. V. 6, p. 107-116, nov. 2006.

FREITAS, L. C. Crítica da organização do trabalho pedagógico e da didática - Campinas, SP: Papirus, 1995.

GEHRES, A. F. - Avaliação em dança nas aulas de educação física: $3^{\circ}$ ciclo das escolas básicas 2,3 do conselho de Oeiras-Portugal Anais do X Congresso de Ciências do Esporte. Goiânia-GO, v. 1, 1997.

KUENZER, A. Z. Desafios teórico-metodológicos da relação trabaIho-educação e o papel social da escola. In: FRIGOTTO, G. (org.).

Educação e crise do trabalho: Perspectivas de final de século. $8^{a}$ ed. Petrópolis: Vozes, p. 55-75,1998.

LABAN, R. - Domínio de movimento - São Paulo: Summus, 1978.

LAKATOS, E. M. - Fundamentos da metodologia científica - ed.

5, São Paulo: Atlas, 2003.

LEONTIEV, Alexis. O Homem e a cultura. In: LEONTIEV, Alexis. 0 desenvolvimento do psiquismo. Lisboa: Horizonte, 1978. p. 261-284.

MALINA, A.; AZEVEDO, A. C. B.; OLIVEIRA, V. M. - CBCE: um coletivo intelectual da Educação Física? Filosofia da práxis, política e ciência em questão. Anais do XV Congresso Brasileiro de Ciências do Esporte e II Congresso Internacional de Ciências do Esporte/ Colégio Brasileiro de Ciências do Esporte. Recife: CBCE, 2007.

MARQUES, I. - Dança na escola: arte e ensino. In: Salto para o futuro. Dança na escola: arte e ensino. Ano XXII - Boletim 2 Abril 2012.

MARQUES, I.. - Dançando na escola. MOTRIZ - Volume 3, Número 1, Junho/1997. 
MARQUES, I.. - Ensino da dança hoje: textos e contextos. São Paulo: Cortez, 1999.

MARX, Karl. Contribuição à crítica da economia política. 2. ed. São Paulo: Expressão Popular, 2008.

PORPINO, K. O; TIBÚRCIO, L. K. O. M. - Cenas urbanas e cenas da dança: compondo novos repertórios pedagógicos no contexto do ensino superior. - Revista Brasileira de Ciências do Esporte. Campinas-SP, v. 28, n. 2, p. 141-154, jan.2007.

REVISTA BRASILEIRA DE CIÊNCIAS DO ESPORTE. Disponível em: http://www.rbceonline.org.br/. Acessado em: mar.2016.

RINALDI, I. P. B. - A dança na Educação Física escolar e a metodologia crítico-superadora - 2011. Disponível em: http:// www.diaadiaeducacao.pr.gov.br/portals/pde/arquivos/238-4.pdf. Acessado em: 20 jul.2016.

SARAIVA, M. C. - Elementos para uma concepção do ensino de dança na escola: a perspectiva da educação estética. - Revisa Brasileira de Ciências do Esporte - Campinas, v. 30, n. 3, p. 157171, 2009.

SAVIANI, D. - Escola e Democracia: teorias da educação, curvatura da vara, onze teses sobre a educação política - 41. ed. Revisada - Campinas, SP: Autores Associados, 2009.

SAVIANI, D. Pedagogia histórico-crítica: primeiras aproximações - Campinas, SP: Autores Associados, 2012.

SBORQUIA, S. P.; GALLARDO, J. S. P. - As danças na mídia e as danças na escola. - Revista Brasileira de Ciências do Esporte. Campinas-SP, v. 23, n. 2, p. 105-118, jan., 2002.

SILVA, W. J. L. - Crítica à Teoria Pedagógica da Educação Física: para além da formação unilateral. $111 \mathrm{f}$. Dissertação de Mestrado em Educação, Faculdade de Educação, Universidade Federal da Bahia, Salvador, 2011.

SOARES, C. E. S. - Realidade e possibilidades do trato com o conhecimento da dança na formação de professores de educação física: uma análise do currículo da UEFS. 47 f. Monografia - 
Curso de Licenciatura em Educação Física, Universidade Estadual de Feira de Santana, 2014.

TAFAREEL, C. N. Z. "Coletivo de Autores: a cultura corporal em questão." Metodologia do Ensino da Educação Física. São Paulo: Cortez, 2012.

\title{
Publisher
}

\begin{abstract}
Universidade Federal de Goiás. Faculdade de Educação Física e Dança. Publicação no Portal de Periódicos UFG. As ideias expressadas neste artigo são de responsabilidade de seus autores, não representando, necessariamente, a opinião dos editores ou da universidade.
\end{abstract}

